\title{
EDITORIAL
}

\section{The interface: crucial for successful noninvasive ventilation}

\author{
M.W. Elliott
}

Noninvasive ventilation (NIV) is a real advance in the management of both chronic and acute respiratory failure. It is the absence of an endotracheal or tracheostomy tube which defines NIV. The development of various interfaces have made the delivery of effective ventilation to patients without intubation possible and a good interface is crucial to success. These can be factory manufactured or customised. Driven largely by the explosion in the diagnosis and treatment of obstructive sleep apnoea there are now a wide variety of different factory-made masks of different designs, shapes, sizes and materials. It is usually possible to find something that suits most individuals and there is seldom a need for an individually made interface. Broadly speaking there are four different types: full face masks (enclose mouth and nose), nasal masks, nasal pillows or plugs (insert directly into the nostrils), and mouthpieces. A review of published studies showed that in acute NIV facial masks predominate $(63 \%)$, followed by nasal masks (31\%) and nasal pillows $(6 \%)$. In contrast for chronic NIV nasal masks $(73 \%)$ are the most commonly used followed by nasal pillows $(11 \%)$, facial masks $(6 \%)$ and mouthpieces (5\%) [1]. More recently the use of a "helmet" has been described in hypoxaemic acute respiratory failure (ARF) with patients receiving continuous ventilation for many days [2]. Nasal masks have less static dead space, are not as claustrophobic and allow expectoration and communication more easily than full face masks. The improvement in arterial blood gas tensions appears to be slower in some studies using nasal masks compared to face masks [3]. A full face mask is usually chosen when there is significant mouth breathing, which is very common in patients with an acute exacerbation of chronic obstructive pulmonary disease (COPD), and at least during the initial phase results in better quality of ventilation, in terms of improved minute ventilation and blood gases [4, 5]. Sometimes, in the post acute situation patients can be encouraged to continue NIV, to maximise the improvement in blood gases, by switching from a full face mask to a less claustrophobic nasal mask. Semi-customised masks consist of a prefabricated frame in which a quick drying filler is injected and afterwards moulded to the patient's face. Moulded masks which use small nasal openings, may have increased resistance, which could decrease ventilation [1].

Minimising leak is the first major challenge in both acute and chronic NIV. Leak results from a poor fit between the mask and the skin or through the open mouth. It reduces alveolar ventilation and synchrony between the patient and the machine, and the quality of sleep during NIV may be compromised [6]. During continuous positive airway pressure leak has been shown to increase nasal resistance [7]; this can be improved by the use of a heated humidifier which also increases comfort and tolerability and it is likely that the same is true during NIV. Continuous monitoring of nonintentional leak and ventilation has been incorporated in

Correspondence: M.W. Elliott, St James's University Hospital, Beckett Street, Leeds, LS9 7TF. Fax: 0113206 6042. E-mail: mark.elliott@, lineone.net newer NIV devices and may help clinicians identify when leak is significant enough to interfere with effective ventilation.

The use of an appropriate sized mask is obvious, but equal attention should be directed towards the choice of the correct size of headgear. The fit of the mask can be improved by applying mask cushions and seal and support rings. The amount of leak should be monitored but however good the interface, some leak is inevitable and it is important that the ventilator should be able to compensate. Leak compensation is limited with volume targeted ventilators; adding a leak to the circuit of these ventilators may result in a fall in tidal volume of $>50 \%$ [8]. However moderate leaks can be compensated by increasing the tidal volume. Pressure targeted ventilators have much better leak compensating abilities with peak inspiratory flow rates of $120-180 \mathrm{~L} \cdot \mathrm{min}^{-1}$. However in tests on a lung model it has been found that leak compensating capabilities differ markedly between different devices [9]. To reduce mouth leaks while wearing a nose mask a chin strap is sometimes tried, but is rarely effective. Another approach is to tape the mouth shut; the effect of this on the quality of ventilation and sleep during NIV has been investigated in patients with chronic respiratory failure [6]. Taping the mouth was associated with a marked reduction of leak, improved ventilation and sleep quality. However there are no reports of mouth taping in patients with ARF and it is unlikely to be acceptable to the majority of patients. Use of a full face mask is the usual remedy for excessive mouth leak.

The second major challenge is finding an interface, which is comfortable and does not cause side-effects. Mask-induced pressure sores, typically over the nasal bridge, usually caused by over tightening the straps, may lead to reduced tolerance. Different dressings have been evaluated to prevent nasal bridge abrasion. Other side-effects, related to the interface include eye irritation and dryness.

The third issue, relating to the interface, is the size of the dead space; on the face of it this is likely to be much larger with noninvasive interfaces than an endotracheal tube. Carbon dioxide $\left(\mathrm{CO}_{2}\right)$ rebreathing has been shown with some home bi-level ventilators that have a single gas delivery circuit and do not contain a true exhalation valve [10, 11]. True exhalation valves may increase the resistance to exhalation and the work of breathing [12]. In this issue of the European Respiratory Journal SAATCI et al. [13] report a very carefully performed bench study of a variety of face masks used with different noninvasive ventilators. In addition to measuring static dead space the authors measured dynamic dead space, which will be affected by flow through the ventilator circuit and mask. A number of important themes emerge which are of practical importance both in informing future mask design and also choice of mode of ventilation and machine settings during NIV. Firstly continuous flow throughout expiration reduced total dynamic dead space to close to physiological dead space with most face masks. Without the maintenance of positive pressure throughout expiration, although dynamic dead space was reduced during NIV, it was to a lesser degree. This is in keeping with the 
observation of FERGUSON and GILMARTIN [11] who showed that once positive end-expiratory pressure, or expiratory positive airway pressure, was reduced below $4-6 \mathrm{cmH}_{2} \mathrm{O} \mathrm{CO}$ rebreathing was markedly increased in the absence of a nonrebreathing exhalation valve. Secondly the position of the exhalation ports affects dynamic dead space; ports over the nasal bridge were best followed by those positioned elsewhere within the mask and then those at the junction between the mask and the ventilator circuit. This is what would be expected theoretically, with the expiratory port situated diametrically opposite the inspiratory port there will be minimal rebreathing whereas if the path of gas flow during inspiration and expiration are the same more rebreathing will occur. When the path of expiration is somewhere in between the same will be true for the degree of rebreathing. In a clinical study of seven patients with COPD ventilated noninvasively moving the path for exhalation was shown to reduce $\mathrm{CO}_{2}$ rebreathing to almost zero [14]. Thirdly there is a poor relationship $(\mathrm{r}=0.36)$ between the static volume of the mask and the dynamic dead space. Even a mask with a static dead space approaching a litre had a dynamic dead space that was little different to other face masks with a much smaller static dead space. This observation is likely to be explained by the streaming effect of gas through the face mask. It may also explain why the "helmet", with an enormous static dead space, can be used effectively for NIV, at least in patients with nonhypercapnic respiratory failure [2]. The effect of flow through the mask may even reduce the dead space to less than that expected during spontaneous breathing without a mask in situ. Finally even masks that do not have ports situated in the optimal place may still perform well, in terms of a small dynamic dead space, probably because of unintentional leak around the nasal bridge; in other words leak between mask and face may be beneficial during NIV in terms of reducing rebreathing [15].

Although carbon dioxide rebreathing has been demonstrated during noninvasive ventilation $[11,14]$ it is not known whether it is of clinical significance or not. One reason why an effect in terms of clinical outcome may not have been seen hitherto is because of unintentional leak from between the mask and the face [15]. The goal of minimising leak remains a key aim for successful noninvasive ventilation both to maximise ventilation but also improve patient ventilator synchrony. As mask and head gear design improves to achieve this end, and unintentional leak reduces, rebreathing could start to impact upon outcome. There seems to be little reason not to position the exhalation port over the nasal bridge and there are other good reasons for the addition of some positive airway pressure during expiration as well as inspiration in terms of reducing the work of breathing [16] and improving gas exchange during sleep [17]. Exhalation ports over the nasal bridge should become the "standard", and some positive pressure maintained through expiration the norm, during noninvasive ventilation.

\section{References}

1. Schonhofer B, Sortor-Leger S. Equipment needs for noninvasive mechanical ventilation. Eur Respir J 2002; 20: 1029-1036.
2. Antonelli M, Conti G, Pelosi P, et al. New treatment of acute hypoxemic respiratory failure: noninvasive pressure support ventilation delivered by helmet - a pilot controlled trial. Crit Care Med 2002; 30: 602-608.

3. Meduri GU, Turner RE, Abou-Shala N, Wunderink R, Tolley E. Noninvasive positive pressure ventilation via face mask - first line intervention in patients with acute hypercapnic and hypoxemic respiratory failure. Chest 1996; 109: 179-193.

4. Navalesi P, Fanfulla F, Frigerio P, Gregoretti C, Nava S. Physiologic evaluation of noninvasive mechanical ventilation delivered with three types of masks in patients with chronic hypercapnic respiratory failure. Crit Care Med 2000; 28: 1785-1790.

5. Brochard L. What is really important to make noninvasive ventilation work. Crit Care Med 2000; 28: 21392140.

6. Teschler H, Stampa J, Ragette R, Konietzko N, BerthonJones M. Effect of mouth leak on effectiveness of nasal bilevel ventilatory assistance and sleep architecture. Eur Respir J 1999; 14: 1251-1257.

7. Richards GN, Cistulli PA, Ungar RG, Berthon-Jones M, Sullivan CE. Mouth leak with nasal continuous positive airway pressure increases nasal airway resistance. $\mathrm{Am}$ J Respir Crit Care Med 1996; 154: 182-186.

8. Smith IE, Shneerson JM. A laboratory comparison of four positive pressure ventilators used in the home. Eur Respir $J$ 1996; 9: 2410-2415.

9. Mehta S, McCool FD, Hill NS. Leak compensation in positive pressure ventilators: a lung model study. Eur Respir $J$ 2001; 17: 259-267.

10. Lofaso F, Brochard L, Hang T, Lorino H, Harf A, Isabey D. Home versus intensive care pressure support devices. Experimental and clinical comparison. Am J Respir Crit Care Med 1996; 153: 1591-1599.

11. Ferguson GT, Gilmartin $\mathrm{M} . \mathrm{CO}_{2}$ rebreathing during BiPAP ventilatory assistance. Am J Respir Crit Care Med 1995; 151: $1126-1135$.

12. Lofaso F, Brochard L, Touchard D, Hang T, Harf A, Isabey D. Evaluation of carbon dioxide rebreathing during pressure support ventilation with airway management system (BiPAP) devices. Chest 1995; 108: 772-778.

13. Saatci E, Miller DM, Stell IM, Lee KC, Moxham J. Dynamic dead space in face masks used with non-invasive ventilators: a lung model study. Eur Respir J 2003; 23: 129-135.

14. Chen R, Zhang X, He G. Modification of facial mask on the dead space effect in non-invasive mask ventilation. Chinese J Tuberculosis Respir Dis 2000; 23: 734-736.

15. Hill NS, Carlisle C, Kramer NR. Effect of a nonrebreathing exhalation valve on long-term nasal ventilation using a bilevel device. Chest 2002; 122: 84-91.

16. Appendini L, Patessio A, Zanaboni S, et al. Physiologic effects of positive end-expiratory pressure and mask pressure support during exacerbations of chronic obstructive pulmonary disease. Am J Respir Crit Care Med 1994; 149: 10691076.

17. Elliott MW, Simonds AK. Nocturnal assisted ventilation using bilevel positive airway pressure: the effect of expiratory positive airway pressure. Eur Respir J 1995; 8: 436-440. 